\title{
As experiências no âmbito do lazer e o princípio da inércia: Uma analogia para pensar sobre os fatores que influenciam a apropriação dos espaços públicos
}

\author{
Aline Tschoke*
}

Simone Rechia **

Karine do Rocio Vieira dos Santos ${ }^{* * *}$

Flavia Gonzaga Lopes Vieira ${ }^{* * * *}$

Luize Moro ${ }^{* * * * *}$

\begin{abstract}
Resumo: O presente artigo buscou compreender a relação estabelecida entre as forças sociais e o uso dos espaços públicos de lazer. A metodologia utilizada foi a participação, registro e descrição das atividades realizadas pelo PELC/UFPR, no período de 2008 e 2009, na região do bairro Uberaba, na cidade de Curitiba-Paraná. Para análise dos dados utilizou-se a analogia do princípio da inércia com o plano social, tendo como principais forças apontadas: as relações sociais, as lideranças e a apropriação. Nesse sentido, aponta-se a necessidade dessas forças serem potencializadas e ampliadas para que possam contribuir com a apropriação dos espaços públicos de esporte e lazer das cidades.

Palavras-chave: Centros de Convivência e Lazer. Políticas Públicas. Valores Sociais.
\end{abstract}

\section{INTRODUÇÃo}

A cidade moderna, segundo Lefebvre (2001), é fruto da ur-

\footnotetext{
* Doutora professora adjunta da Universidade Federal do Paraná. Curitiba, PR, Brasil. E-mail: simone@ufpr.br

** Graduanda em Educação Física-Licenciatura na Universidade Federal do Paraná. Pesquisadora do Grupo de Estudos e Pesquisa em Lazer, Espaço e Cidade(GEPLEC) . Curitiba, PR, Brasil. E-mail: karine_ufpr@yahoo.com.br

${ }^{* * *}$ Mestre em Educação Física. Pesquisadora do -Grupo de Estudos e Pesquisas em espaços lazer e cidade (GEPLEC). Curitiba, PR,Brasil. E-mail: aline_tschoke@yahoo.com.br

**** Mestre em Educação Física. Professora da rede estadual de ensino do Paraná. Curitiba, PR, Brasil. E-mail: flaviaglv@yahoo.com.br

${ }_{* * * \star \star}$ Mestranda em Educação Física na Universidade Federal do Paraná. Participante do grupo de estudos do GEPLEC. Curitiba, PR, Brasil. E-mail: luizemoro@yahoo.com.br
} 
banização acelerada desencadeada pelo processo de industrialização. Neste contexto, as grandes cidades surgiram e trouxeram consigo, entre outras coisas, a aglomeração de pessoas num só lugar a fim de encontrar trabalho e melhores condições de vida. Esse cotidiano compartilhado no meio urbano gera os tempos e espaços da família, do trabalho, do lazer, que se inter-relacionam e podem se potencializar nos espaços públicos de lazer, como praças, parques, bosques, centro culturais, etc. Tais espaços têm o propósito de possibilitar, entre outras coisas, o encontro entre os sujeitos moradores dessas grandes cidades.

Devemos considerar que nesses tempos e espaços, no meio urbano, segundo Lefebvre (2001), há a existência de continuidades e descontinuidades. As continuidades tendem a ocultar temporariamente algumas características específicas de ordem global (econômica, política, cultural, ambiental). Já as descontinuidades marcam o local, o diferente, o peculiar, o resultado da interação entre as relações sociais mais gerais e as relações imediatas dos sujeitos e dos grupos. Dessa forma, alguns estudos dos fenômenos urbanos buscam desvendar tais continuidades e descontinuidades a fim de superar obstáculos e dilemas, compreendendo que existem processos globais, mas também brechas ao nível de relações imediatas, pessoais e interpessoais:

Entre as fissuras de uma "realidade" que muito fre-
qüentemente é considerada como um ovo ou como
uma página inteiramente escrita, a análise pode
agora perceber por que e como processos globais
(econômicos, sociais, políticos, culturais) modela-
ram o espaço urbano e modelaram a cidade, sem
que a ação criadora dos sujeitos decorra imediata
e dedutivamente desses processos (LEFEBVRE,
2001, p. 57).

Essa "ação criadora dos sujeitos" influencia os tempos e os espaços urbanos, gerando a apropriação dos lugares por grupos diversificados. Graças a esse processo "[...] a cidade não pode ser concebida como um sistema significante, determinado e fechado" (LEFEBVRE, 2001, p. 59), mas sim, como propõe o autor: “[...] como sendo projeção da sociedade sobre um local, isto é, não apenas sobre o lugar sensível como também sobre o plano específico,

Movimento, Porto Alegre, v. 17, n. 01, p. 117-136, janeiro/março de 2011. 
percebido e concebido pelo pensamento, que determina a cidade e o urbano." (LEFEBVRE, 2001, p. 62).

Pellegrin (2004, p. 74) complementa essas afirmações ao apontar que as diferentes correlações entre as forças econômicas e políticas, no espaço em que vivemos, geram as "[...] relações de poder e de controle, que se estabelecem sobre a cidade e acabam determinando não apenas o desempenho, mas também o uso que se faz dela".

Já nas suas inúmeras possibilidades arquitetônicas, as cidades constituem-se por espaços principais e derivados, os quais conduzem as formas de uso. Para Jacobs (2000), os usos principais funcionam como âncoras e atraem as pessoas para determinados lugares das cidades. Os usos derivados resultam da dinâmica social que gira entorno desses espaços arquitetônicos. Essa combinação de usos é que dá vida aos lugares. Ressaltamos aqui a importância dessa dinâmica nos espaços públicos, nos quais o acesso muitas vezes é livre a todos os cidadãos e as experiências no âmbito do lazer pautam, em algumas situações, os objetivos da sua existência. Esses locais têm a apropriação como ponto fundamental do seu papel na sociedade. Entretanto, para que tal papel seja realmente efetivo faz-se necessário que seus usos tenham sentido e significado para a comunidade que deles usufruem.

Tendo em vista tais reflexões, daí a relevância social do estudo das experiências de lazer em espaços públicos, a partir da práxis ${ }^{1}$ do Programa de Esporte e Lazer da Cidade $^{2}$ (PELC) - UFPR, vinculado ao Grupo de Estudos e Pesquisas em Lazer, Espaço e Cidade ${ }^{3}$ (GEPLEC) durante o processo de desenvolvimento de suas ações na Vila

\footnotetext{
1 Compreendemos assim as ações do PELC, visto que buscamos a conexão entre a teoria compreendida e discutida no interior do Grupo de Estudos em Lazer, Espaço e Cidade, com a presença de todos os envolvidos no Programa, e as experiências práticas no bairro Uberaba. 2 Programa implantado e gerenciado pela Secretaria Nacional de Desenvolvimento do Esporte e do Lazer, SNDEL, do Ministério do Esporte, neste caso, em parceria com a Universidade Federal do Paraná, sendo o núcleo em questão localizado na cidade de Curitiba, em uma região do bairro Uberaba.

${ }^{3}$ O GEPLEC está vinculado ao CEPELS (Centro de Estudos e Pesquisas em Esporte, Lazer e Sociedade), Departamento de Educação Física da Universidade Federal do Paraná.
}

Movimento, Porto Alegre, v. 17, n. 01, p. 117-136, janeiro/março de 2011. 
Audi ${ }^{4}$, localizada no bairro Uberaba, na cidade de Curitiba-Paraná. Desse contexto emerge e se desenvolve a temática abordada neste trabalho, que busca compreender qual a relação que se estabelece entre forças sociais e a (des)apropriação ou apropriação dos espaços públicos de lazer.

Parte-se da ideia de que a apropriação dos espaços públicos da Vila Audi, "só se mantém e, portanto, depende do significado que a comunidade thes atribui" (RECHIA; FRANÇA, 2006, p. 67). Sendo assim, a apropriação é resultado de uma teia de relações que envolve comunidade-espaço e comunidade-comunidade.

Nessa perspectiva compreendemos como forças sociais as ações individuais e coletivas emergentes da sociedade, que de alguma forma irão agir sobre a mesma. Tomando o caso específico dos espaços públicos planejados para o tempo/espaço do lazer, isso ocorre em dois sentidos: na apropriação ou na desapropriação por meio de diversificadas práticas socioculturais.

Neste estudo percebemos que a apropriação dos espaços públicos da Vila Audi surgiu a partir das vivências lúdicas agregadas à participação de lideranças locais, as quais refletiram em uma atitude diferenciada em relação ao cotidiano da comunidade. Deste modo, as experiências no âmbito do lazer trouxeram consigo valores como solidariedade e respeito, inclusive ao espaço, que, sendo público, passou a gerar um sentido de pertencimento a todos, a partir dessas experiências.

Dessa forma, vemos no tempo e espaço do lazer a possibilidade de compreender o nível de integração de um cidadão com sua cidade, mais especificamente com os espaços públicos. Por meio das formas de uso, dos cuidados, da responsabilidade compartilhada entre usuários e poder público, percebemos também como a comunidade e as lideranças locais se comprometem com tais espaços.

\footnotetext{
${ }^{4}$ A "Vila Audi" faz parte de uma região de vulnerabilidade social denominada "Bolsão de Pobreza Audi/União", composta por oito vilas distribuídas em aproximadamente três milhões de metros quadrados, com moradias precárias, localizadas aos arredores do rio Iguaçu, no bairro Uberaba/Curitiba/Paraná.

Movimento, Porto Alegre, v. 17, n. 01, p. 117-136, janeiro/março de 2011.
} 
Nesse sentido, ao refletirmos sobre as forças sociais e suas relações com a apropriação dos espaços públicos, observamos que é possível fazer uma analogia entre o plano social e uma das propriedades físicas da matéria, definida por Isaac Newton, o qual afirma que "na ausência de forças todo corpo fica como está, parado se estiver parado e em movimento se estiver em movimento", essa propriedade da matéria é conhecida como inércia (GASPAR, 2007, p. 80).

Tendo em vista a necessidade de apurarmos os olhares para compreendermos as nuances que ocorrem quando tratamos de um fenômeno sociológico em contraste com um fenômeno da física, percebemos a importância de ressaltar algumas características que podem ser atribuídas à "inércia social" quando discutida no âmbito do lazer.

Em primeiro lugar salientamos que diferentemente da lei de Newton, no plano social não é possível a existência do vácuo, isto é, a ausência de forças, no sentido da apropriação dos espaços, compreendidas aqui como propulsoras. Ou na direção oposta, induzindo a desapropriação, à qual denominamos forças de resistência. Enfim, no plano social, a todo o momento, forças sociais estão atuando seja no sentido da apropriação ou da desapropriação.

Ressaltamos que nesse plano não há leis estanques, sendo assim, não se trata de uma lógica de ação e reação. O princípio da inércia, neste caso, não poderia ser utilizado na sua forma original para descrever um fenômeno sociológico, visto que a lei da física é uma regra geral, enquanto a "inércia social" refere-se à singularidade de cada local.

Essa visão parte do pressuposto de que cada pessoa possui sua individualidade e certo nível de autonomia perante suas escolhas. Os sujeitos muitas vezes podem escolher onde querem ou não estar, mas precisamos atentar para o fato dessas escolhas serem construídas historicamente e influenciadas pela sociedade na qual estamos inseridos.

Percebemos também que o movimento ou o vazio gerado nos espaços públicos de lazer pode ser iniciado ou retido por diversas questões, dentre elas destacamos a violência, a moda vigente, a insegurança, os hábitos, a autonomia individual. Porém visualizamos

Movimento, Porto Alegre, v. 17, n. 01, p. 117-136, janeiro/março de 2011. 
que também dependem das forças sociais geradas pelas lideranças formais e informais 5 .

Isso porque pudemos observar durante o desenvolvimento do PELC/UFPR que tais forças movimentaram as ações, tornando-se, muitas vezes, fundamentais para a aceitação e aderência da comunidade à proposta de atividades do programa.

Considerando tais ressalvas quanto à Lei da Física e às forças sociais, podemos inferir que nossa analogia situa-se no fato de que verificamos a tendência de uma maior facilidade na apropriação dos espaços quando estes já vêm sendo apropriados pela comunidade, e uma dificuldade de apropriação dos que possuem pouco uso. $\mathrm{Na}$ Vila Audi existe, a todo o momento, forças sociais atuantes, assim sendo, o movimento gerado nos espaços decorrentes de tais forças é que os torna apropriado ou desapropriado.

Jacobs (2000), ao analisar os espaços das cidades americanas, reforça esse dado ao concluir que quanto mais um lugar for apropriado, mais ele tende a ser e permanecer apropriado. Já um lugar desapropriado, tende a continuar desapropriado, a não ser quando existir forças que mudem essa realidade. Nas palavras da referida autora: "Nas cidades, a animação e a variedade atraem mais animação; a apatia e a monotonia repelem a vida" (JACOBS, 2000, p. 108).

Nesse sentido, é importante perceber quais são as forças atuantes nos espaços que permitem que eles sejam "vivos" ou sofram do "mal do vazio". Partimos do pressuposto de que pelo menos duas forças atuam sobre a apropriação, quais sejam: a infraestrutura do espaço e os sujeitos agindo primeiramente no plano individual e depois no plano coletivo.

A primeira diz respeito ao planejamento e à estrutura física dos espaços que podem influenciar no uso ou desuso. Um lugar que possua equipamentos variados, acessibilidade, segurança e manutenção tende a ser mais apropriado, pois o uso desse lugar se torna facilitado.

\footnotetext{
${ }^{5}$ Compreendendo a liderança formal como a ação de "líderes" vinculados a determinados grupos em razão de alguma instituição que os confere certo poder sobre este grupo. Já a liderança informal ocorre quando o "líder", isto é, o sujeito que possui a autonomia individual necessária para influenciar outras pessoas, o faz a partir de sua ação intrínseca e cotidiana.
}

Vovimento, Porto Alegre, v. 17, n. 01, p. 117-136, janeiro/março de 2011 
Santos (apud LUCHIARI, 1996, p. 217) afirma que o espaço é um "condicionante condicionado", pois sua organização sugere ou muitas vezes impõe certos comportamentos. Porém também é condicionado, visto que pode ser apropriado de diferentes formas além daquela para qual foi planejado. Ainda de acordo com o autor, "o espaço não é um pano de fundo impassível e neutro. Assim este não é apenas um reflexo da sociedade nem um fato social", (apud LUCHIARI, 1996, p. 217) mas a relação entre ambos.

A segunda diz respeito à autonomia individual, a qual poderá gerar forças coletivas. Salientamos que a autonomia individual é pré-requisito para a constituição de forças coletivas, pois consiste na possibilidade do sujeito ter um projeto de vida singular, definir e defender a própria dignidade, mesmo diante de obstáculos com que todos se deparam, em variados graus. Uma vez conquistado esse direito, poderão surgir forças coletivas, as quais se potencializam quando conseguimos pensar e agir para além de nós como indivíduos. Para Bauman e May (2010, p. 24), faz-se assim uma "apologia do individual, mas não do individualismo". Significa primeiro viver de forma relativamente plena a vida pessoal para depois viver de forma relacionada e consequentemente situar-se em redes de relações sociais.

Dessa maneira, as redes de relações sociais se constituem a partir do agrupamento de sujeitos que se unem por afinidades e com interesses comuns. Tais redes possibilitam a potencialização de forças coletivas capazes de atuar no campo social e político. Para Bauman e May (2010, p. 27), "os sujeitos unidos coletivamente geram a capacidade de resistir à coercitiva regulação da vida individual, é o poder dos sem poder". Nesse sentido, a força coletiva pode transformar um espaço que vive na inércia do vazio em um lugar ativo e apropriado.

Os espaços públicos de lazer são lugares propícios para impulsionar essas forças coletivas, pois proporcionam o encontro entre sujeitos com interesses comuns. Nesse sentido, percebemos que tais forças coletivas podem gerar as lideranças comunitárias, as quais surgem espontaneamente da relação entre alguns sujeitos e a comunidade.

Movimento, Porto Alegre, v. 17, n. 01, p. 117-136, janeiro/março de 2011. 
Os espaços públicos da Vila Audi muitas vezes tornaram-se palco de manifestações políticas e culturais, durante as experiências do PELC, o que reforça a importância de compreender esse fenômeno.

\section{Metodologia}

Para alcançar os objetivos deste artigo foram seguidos os seguintes passos metodológicos: (1) Participação nas atividades desenvolvidas no Programa; (2) Registro fotográfico das oficinas e eventos; (3) Descrição densa em diário de campo; (4) Levantamento bibliográfico da literatura relacionada às temáticas da apropriação, espaços públicos de lazer e grupos sociais; e (5) Análise dos fatos descritos. O espaço delimitado para pesquisa foi a Vila Audi no bairro Uberaba, Curitiba-PR.

Agregados às análises das ações do PELC/UFPR, estão também os resultados obtidos no projeto intitulado "Diagnóstico de Políticas Públicas de Esporte e Lazer do Estado do Paraná: estudo sobre espaços e equipamentos", financiado pela REDE CEDES/UFPR. Nesses estudos e ações detectamos algumas problemáticas na oferta de programas de esporte e lazer nas cidades e ainda que a preservação de ambientes naturais no meio urbano (praças e parques) está diretamente ligada com as formas de apropriação no âmbito das experiências do Lazer.

Os procedimentos metodológicos citados aconteceram simultaneamente com o desenvolvimento das ações práticas do PELC na Vila Audi. As oficinas desenvolvidas e analisadas nessa comunidade foram: práticas corporais lúdicas, jogos e brincadeiras, expressão corporal, esporte, pintura, desenho e fotografia, paisagismo, artesanato, dança de salão, educação ambiental, ginástica, práticas circenses, capoeira e hip-hop.

Os eventos realizados foram treze no total, intitulados: I Festival de atividades lúdicas, Grito de carnaval da comunidade, Ginástica especial do dia das mulheres, Aniversário de Curitiba, 1. Intervenção PELC no bosque, Forró do PELC: Aulão de dança de salão, Campeonato de vôlei, Projeto pipas, Domingo no bosque com o PELC, II Festival de atividades lúdicas, Cuidar da saúde também é brincar, Refletindo

Wovimento, Porto Alegre, v. 17, n. 01, p. 117-136, janeiro/março de 2011. 
sobre a criança, o brincar e a cidade, e a Festa da comunidade: cultura e lazer para todas as idades.

Tendo como base a prática pedagógica dos agentes sociais, foi possível analisar os fatos ocorridos durante o desenvolvimento do PELC e perceber a dinâmica das forças sociais presentes nos espaços de ação: a escola, o bosque, a praça, a associação de moradores, a ONG, o centro de saúde, a rua, entre outros locais. Fatos que nos possibilitaram elencar e discutir as seguintes categorias de análises.

\section{As FORÇAS SOCIAIS E A RELAÇÃO COM A APROPRIAÇÃO DOS ESPA- ÇOS DE LAZER NA VILA AUDI}

Entendemos que o fenômeno do lazer materializado na Vila Audi nos possibilitou compreender os sujeitos e as relações sociais que se estabelecem nos grupos, nos lugares e no bairro.

Marcassa e Mascarenhas (2005, p. 257) afirmam que é nesse tempo e nesse espaço que:

Os jovens criam e reforçam seus laços de identidade social, que as crianças, por meio da atividade lúdica, interpretam e ressignificam o mundo que as cerca, que os adultos tecem suas relações sociais e renovam valores e comportamentos que fundamentam os princípios éticos, estéticos e políticos que regem a sociedade.

Partindo dessa perspectiva, e das nossas observações, o fenômeno do lazer se apresentou como uma possível prática de liberdade. Observamos que no tempo e espaço de algumas experiências nesse âmbito os sujeitos foram capazes de analisar e fazer crítica a questões relacionadas à sociedade e à sua própria vida. A busca pelo direito ao lazer também se fizera presente em algumas discussões na Associação de Moradores, ao identificarem que a própria Associação era um local com grande carência na oferta de atividades socioculturais. Nesse espaço, as lideranças da comunidade juntamente com os bolsistas do PELC buscaram por diversas vezes melhorar o ambiente da Associação, buscando meios na própria comunidade

Wovimento, Porto Alegre, v. 17, n. 01, p. 117-136, janeiro/março de 2011. 
e também recorrendo ao poder público, por meio da elaboração de documentos reivindicatórios.

Percebemos, dessa forma, que as lideranças comunitárias formais têm a compreensão desse direito garantido pela Constituição Brasileira, onde aparece, de fato, como um direito social: "São direitos sociais a educação, a saúde, o trabalho, a moradia, o lazer, a segurança, a previdência social, a proteção à maternidade e à infância, a assistência aos desamparados, na forma desta Constituição." (BRASIL, 2007, grifo nosso).

Sabendo disso, tentamos elencar algumas análises que emergiram das relações sociais estabelecidas em diferentes ambientes do bairro.

Em primeiro lugar, as relações humanas, as quais aconteceram em determinados espaços e tempos, e possibilitaram a potencialização da vida urbana. No caso dos espaços públicos de lazer essas relações foram ainda mais intensas, pois "[...] oportunizaram entre outras coisas a sociabilidade, a prática esportiva, a atividade física, a brincadeira, o desenvolvimento cultural, assim como os confrontos, embates e tensões sociais que surgiram na produção dessas experiências (RECHIA; FRANÇA, 2006, p. 62).

Nesse sentido, vemos que a categoria "espaço" transcende a estrutura física e dimensões numéricas, passando a exercer uma força nas relações sociais.

O espaço torna-se, segundo Rechia e França (2006, p. 63), "[...] um importante instrumento analítico e ferramenta interpretativa", portanto, a partir dos estudos do espaço, foi possível compreender os códigos, símbolos e significados a eles atribuídos e que permitiram compreender as relações cotidianas que nele se estabeleceram.

Em segundo lugar, a relação que surge é a dimensão do lugar. Esse conceito foi discutido por Santos (2006), o qual compreende o lugar como o "mundo vivido" no qual se manifestam um cotidiano compartilhado entre as pessoas e as instituições.

Para Rechia e França (2006, p. 63), "o que começa como espaço indiferenciado transforma-se em lugar à medida que o conhecemos

Tovimento, Porto Alegre, v. 17, n. 01, p. 117-136, janeiro/março de 2011. 
melhor e o dotamos de valor". Sendo assim, entendemos que as experiências de lazer vividas nos espaços públicos da Vila Audi possibilitaram uma nova maneira de perceber a cidade e o estreitamento na relação cidade-cidadão. Percebemos isto no bosque próximo à

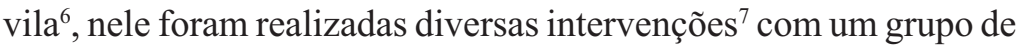
crianças vinculadas ao programa PETI ${ }^{8}$ (Programa de Erradicação do Trabalho Infantil). Notamos que, após essas intervenções, houve certa mudança de comportamento delas em relação àquele espaço.

Aparentemente as crianças não percebiam o bosque como uma possibilidade de espaço para o seu tempo de lazer, isto é, não havia nesse grupo um sentimento de pertencimento em relação ao bosque e aos equipamentos ali disponíveis. Mas a partir das experiências vivenciadas nesse espaço, percebemos que o bosque passou a ter um outro significado e assim fazer parte do mundo vivido dos alunos em questão, tornando-se um "lugar".

Nesse sentido, ao associarmos essas categorias localizamos uma terceira dimensão - a apropriação -, que está relacionada aos usuários que são os responsáveis por atribuir aos espaços sentidos e significados. Sem essa dimensão o espaço se torna vazio e perde sua função primordial.

Assim, apropriação pode ser entendida como:

$[\ldots]$ atividade humana que se realiza pelo homem em torno do ser humano e nele engloba seus sentidos, sensibilidade, necessidade e desejos. Realiza-se com base em uma estratégia que escapa à equivalência (imposta pela troca) e ao homogêneo (imposto pela norma) e faz aflorar o diferente - é a multiplicidade na heterogeneidade, o que acentua seu caráter apropriador, isto é, o homem apropria-se das condições exteriores, transformando-as (CARLOS, 2001, p. 216, apud FRANÇA, 2007, p. 3).

\footnotetext{
${ }^{6}$ Localizado ao lado de um Colégio Estadual, na Rua Esperidião Kalluf, 125. ${ }^{7}$ Realizadas entre os meses de abril e dezembro de 2009.

8 O PETI é um programa do Governo Federal que visa erradicar todas as formas de trabalho de crianças e adolescentes menores de 16 anos e garantir que frequentem a escola e atividades socioeducativas. Disponível em: <www.portaldatransparencia.gov.br>. Acesso em: 17/2/2011.

Movimento, Porto Alegre, v. 17, n. 01, p. 117-136, janeiro/março de 2011.
} 
Novamente recorremos ao bosque próximo à Vila Audi para exemplificar a apropriação, onde durante um dos eventos do PELC ele foi (re)significado por meio de práticas que não eram comuns naquele espaço. Uma delas foi a instalação de uma balança de pneu, uma das atrações mais movimentadas do evento. Outro exemplo de (re)apropriação ocorreu nas praças da Vila, onde os bolsistas do PELC realizavam periodicamente pequenos passeios com grupos diferenciados. Nesses passeios muitos equipamentos já existentes foram utilizados para outros fins que não aqueles a que tinham sido planejados, como por exemplo, as quadras de bocha, que nos passeios foram utilizadas para brincadeiras de maior interesse das crianças.

Sendo assim, Smolka (2000, p. 32) acrescenta às definições anteriores que o ato de apropriar-se pode ser definido como tornar próprio, salientando que "nem sempre esse tornar próprio coincide com o tornar adequado as expectativas sociais. Existem modos de tornar próprio, de tornar seu, que não são adequados ou pertinentes para o outro". Nesse sentido, a autora enfatiza que a apropriação é permeada de tensões sociais, pois

\begin{abstract}
Aprofundando nossas análises, notamos que muitas tensões se instalam nas várias possibilidades de significação (e modos) de apropriação, tornar próprio, de si mesmo, atribuir pertença ou propriedade, assumir, tornar adequado, pertinente, desenvolver capacidades e meios (instrumentos, modos) de ação, de produção. Alguns desses modos e significados, nenhum deles ou todos eles podem (ou não) coincidir. Tais tensões produzem diferentes (efeitos de) sentidos, dependendo das situações, das posições dos sujeitos nas relações. Alguns modos de participação/apropriação podem adquirir visibilidade analítica, enquanto outros permanecem simplesmente impossíveis de traçar (SMOLKA, 2000, p. 36).
\end{abstract}

Essas tensões sociais puderam ser percebidas diversas vezes nos espaços da Vila Audi. Existem alguns espaços demarcados, verdadeiros territórios controlados, com suas características próprias, ou seja, existem, em determinados períodos do dia, horários ditos seguros para transitar pelas ruas, os quais são limites imaginários

Movimento, Porto Alegre, v. 17, n. 01, p. 117-136, janeiro/março de 2011. 
que autorizam ou não grupos a frequentar ações no âmbito do lazer, agregado a isso há o toque de recolher que é capaz de fechar até mesmo o espaço da escola.

\section{As RELAÇõES SOCIAIS EM AÇÃo NOS ESPAÇOS DE LAZER DA VILA AUDI-UNIÃO: A FORÇA DAS LIDERENÇAS}

Tendo em vista a analogia com o princípio da inércia, admitimos neste momento que as influências das forças sociais impulsionam ou se opõem à apropriação dos espaços da Vila Audi, e mostraremos como essas forças influenciam no movimento gerado. Um exemplo disso está no fato de que muitas vezes a presença do "líder", formal ou informal, trouxe vida aos espaços nos momentos em que a autonomia individual ou o desejo gratuito não apontava no sentido da apropriação do espaço. Isto é, quando os sujeitos pareciam não se sentirem seguros a participar de determinada atividade, essa segurança surgia estimulada por outra pessoa, como uma professora, um amigo, um familiar, que chamavam à participação, e influenciavam a ativa apropriação do espaço. A partir da influência dessas possíveis lideranças, o espaço ganhava movimento e, com isso, aumentavam as chances de mantê-lo vivo.

Fato que deu início a essa percepção ocorreu na Associação de Moradores. Num primeiro diagnóstico, observamos que aquele espaço estava inerte, parado, necessitando de forças sociais que gerassem movimento, isto é, a apropriação. Implantamos uma oficina no espaço, e percebemos que durante as atividades que ocorriam uma vez por semana, quando a liderança formal do bairro exercia sua influência sobre as crianças, no sentido de convidá-las à participação, estas atendiam ao chamado. Visivelmente isto acontecia predominantemente em razão da força social exercida por esta liderança e não necessariamente pelas atividades desenvolvidas. No decorrer da oficina, percebia-se uma facilidade das crianças da rua de interessarem-se pelas brincadeiras que ocorriam naquele espaço, isto porque muitos viam ali seus amigos, irmãos, conhecidos, transmitindo assim certa sensação de segurança em também participar das atividades.

Movimento, Porto Alegre, v. 17, n. 01, p. 117-136, janeiro/março de 2011. 


\section{Antigos Originais}

Aline Tschoke, Simone Rechia et al.

Jacobs (2000, p. 40) nos mostra que a presença dos sujeitos nos espaços das cidades estimula o movimento. De acordo com a autora, isso decorre do prazer dos indivíduos de presenciar esse fluxo contínuo. Podemos notar na Vila Audi que o movimento, isto é, o fluxo de pessoas em determinados espaços, se constituiu como uma força capaz de atrair mais pessoas, no entanto, o inverso também pode ser considerado, como no caso descrito da Associação de Moradores.

Nos eventos proporcionados pelo PELC, em especial o realizado em razão do aniversário da cidade de Curitiba, era nítida a questão do sucesso do evento somente após o início do processo de intervenção. Muitas pessoas, ao passarem pela rua, paravam após localizarem alguns conhecidos que ali estavam reunidos. Também eram estimuladas pelo som, pelo movimento gerado na Praça. Assim paravam para acompanhar, algumas só por alguns momentos e outras acabavam participando das atividades.

Outra força atuante nos espaços foram os usos combinados que propiciavam o movimento e a apropriação. De acordo com Jacobs (2000), para que um espaço possua uma diversidade de pessoas circulando pelos lugares, é preciso que esses espaços sintetizem mais de uma atividade. A escola da Vila Audi e seu entorno podem ser considerados um exemplo de uso combinado. Como esta instituição funciona em período integral (Ensino Fundamental) e noturno (Educação de Jovens e Adultos), e ainda com projetos sociais nos finais de semana, isso possibilita que esse espaço esteja sempre com fluxo de pessoas, sendo considerado pela população como um dos espaços mais seguros da região.

Jacobs (2000, p. 157) ressalta que a segurança pode ser determinante para usos combinados. Para a autora, "a diversidade é natural às grandes cidades, mas é preciso que além de cuidar para que a cidade não seja compreendida apenas em usos separados e sim em usos misturados ou combinados, oferecer opções de comércio, atrativos culturais, empresas, e escolas, e também priorizar a segurança pública". Ressaltamos que a segurança dos sujeitos frequentadores das ruas, calçadas e espaços de esporte e lazer é fundamental para a existência e a continuidade dessa diversidade de usos.

Movimento, Porto Alegre, v. 17, n. 01, p. 117-136, janeiro/março de 2011. 
Na Vila Audi, a questão da violência é muito acentuada. É um bairro com a presença de gangues, tráfico de drogas, desemprego, moradias precárias, dentre outros. Dessa forma, a sensação de insegurança é uma constante. Em determinados horários o receio de permanecer em ambientes que não oferecem segurança, na maioria das vezes, minava as possibilidades de apropriação dos espaços. Percebemos esse fato quando houve a tentativa de implantar oficinas esportivas numa das praças, num horário em que o sol já está se pondo. Muitos dos alunos não puderam participar das atividades em razão do receio de seus pais que eles permanecessem nesse local. Com isso o espaço permanecia esvaziado e consequentemente aumentava a sensação de insegurança.

Nesse sentido, Jacobs (2000) nos traz mais uma contribuição quando se refere aos olhos atentos. Esta força social diz respeito à sensação de segurança provocada quando um espaço encontra-se apropriado e, portanto, vigiado pelos frequentadores. Podemos entender, então, que quanto mais pessoas se apropriarem dos espaços públicos, mais estes lugares oferecerão segurança para os cidadãos. Esse processo que ocorre no espaço torna-se um ciclo que ao ser esvaziado passa a ser inseguro e passa a ser inseguro por ser esvaziado.

\section{APROPRIAÇÃO, RELAÇÕES SOCIAIS E LIDERANÇA: POSSÍVEIS ELOS FACILITADORES PARA O EXERCÍCIO DO DIREITO AO LAZER}

Para que a dinâmica das forças sociais fortaleça o sentido de apropriação dos espaços públicos, observa-se a necessidade fundamental da articulação de algumas dimensões, são elas: as pessoas, o ambiente, as condições de trabalho, o acesso, as possibilidades de educação e as políticas públicas setoriais. Vale ressaltar que o fato de optarmos por determinados espaços de lazer partem de nossa liberdade de escolha e dessas dimensões articuladas entre si. Nesse sentido, Bauman e May (2010, p. 36) nos mostram que "nossa liberdade de agir no presente é conformada por nossas circunstâncias passadas e experiências acumuladas". Tais experiências se originam basicamente dos grupos a que pertencemos, o qual muitas vezes não é uma opção de livre escolha. Para os mesmos autores "talvez integremos este ou

Movimento, Porto Alegre, v. 17, n. 01, p. 117-136, janeiro/março de 2011. 
aquele grupo pura e simplesmente por ali ter nascido. $\mathrm{O}$ grupo que nos define, nos ajuda a orientar nosso comportamento [...] (BAUMAN; MAY, 2010, p. 38).

Sendo assim, pode-se inferir que se certo indivíduo pertence a um grupo o qual não tem como hábito a fruição dos espaços públicos de lazer, dois caminhos tornam-se possíveis: aceitar e acatar a identidade do grupo ou procurar brechas para novos tipos de comportamentos.

A partir da formação dos grupos estabelecem-se as redes sociais, que se constituem como "um sistema de modos e elos, uma estrutura sem fronteiras, uma comunidade não geográfica" (MARTELETO, 2001, p. 72). Ao salientar as redes como não geográficas, o referido autor retira do espaço a determinação sobre as redes, porém Carlos (apud RECHIA, 2003) nos mostra que o espaço público, geográfico, pode sim redefinir as relações sociais, pois, atualmente, as novas morfologias do espaço "agem sobre a constituição da identidade cidadão/cidade, indicando que as novas formas indicam novos conteúdos, novos usos e modos de uso". Estabelecendo assim uma conexão muito próxima do espaço com as relações sociais.

Nesse contexto se apresenta a figura do "líder", que ocupa uma função de poder frente à rede a que pertence, inclusive no tempo e espaço do lazer. Dessa maneira, as lideranças do bairro não estão concentradas somente em ambientes institucionalizados da Vila Audi, pois a força social da liderança individual se mostrou atuante em diferentes espaços e tempos. Foi possível perceber em aulas do contra-turno escolar que, de maneira informal, quando determinado aluno, que exercia sua liderança sobre o grupo, demonstrava interesse por alguma atividade, a maioria do grupo fazia o mesmo. Assim, se ele não se interessasse, o grupo repetia a sua atitude.

Infere-se, portanto, que o exercício do direito ao lazer está diretamente relacionado com a apropriação dos espaços públicos, a qual é influenciada por diferentes fatores socioculturais.

Movimento, Porto Alegre, v. 17, n. 01, p. 117-136, janeiro/março de 2011. 


\section{CONSIDERAÇÕES FINAIS}

Considerando a "inércia social" como uma possibilidade de perceber como se dá a apropriação dos espaços públicos de lazer, ressaltamos a relação que o exercício da liderança tem com esta dinâmica. Conscientemente ou não de que estão proporcionando forças sociais, as lideranças influenciam a vivência do lazer nos espaços públicos. Isto ocorre, por exemplo, quando os meninos da rua passam nas casas uns dos outros chamando para o futebol, quando mães levam seus filhos para brincar nos parquinhos das praças, ou formalmente quando professores utilizam destes espaços para suas aulas. Esses sujeitos usam sua influência para atrair pessoas a determinados locais, atividades e até a reflexões específicas.

Observando e constatando esse fato, compreendemos que uma das atribuições dos educadores é perceber os possíveis líderes em meio aos grupos de trabalho. Tais lideranças deverão ser potencializadas e ampliadas para que possam contribuir e facilitar o exercício da cidadania, pois serão eles, no seu cotidiano, multiplicadores da consciência do direito ao lazer ao agirem como forças sociais. É importante ressaltar que a valorização do líder não pode desconsiderar a autonomia dos outros sujeitos envolvidos nas ações.

Por fim, cabe considerar aqui também as transformações que ocorrem a todo instante quando se trata de fenômenos sociológicos. $\mathrm{O}$ fato de a inércia ser rompida em determinados momentos não implica na manutenção desta situação. Como já dissemos, caso surja uma força social mais forte a situação se modificará. Desse modo, se almejamos uma sociedade que perceba os espaços públicos de lazer como locais de inúmeras possibilidades criativas de práticas lúdicas, devemos potencializar as lideranças que estão diretamente ligadas nessa relação. Nesse sentido, é importante perceber quais são as forças atuantes nos espaços que permitem que eles sejam "vivos" ou sofram do "mal do vazio". Buscar a autonomia do cidadão agregada às ações coletivas, nesse caso, parece a forma mais eficaz de promover a (re)apropriação ou a manutenção do uso dos espaços públicos de lazer, de forma que a comunidade envolvida compreenda as vantagens das experiências, e dos tempos de lazer que os cercam.

Movimento, Porto Alegre, v. 17, n. 01, p. 117-136, janeiro/março de 2011. 


\begin{abstract}
Experiences in the field of leisure and the principle of inertia: An analogy for thinking about factors that influence the appropriation of public spaces Abstract: This article arises from researches and reflections of the Studies and Researches in in Sport, Space and the City's Group (GEPLEC), after the development of the program Sport and Leisure of the City (Pelco) - UFPR, between 2008 and 2009, in Vila Audi's region in Curitiba. Performing an analogy with the principle of inertia, in relation to the social plan is proposed to reflect the influence of social forces in the appropriation of public spaces for leisure. Aims to elucidate aspects, which facilitate / or hinder the appropriation of public leisure spaces.

Keywords: Centers of Connivance and Leisure. Public Policies. Social Values.
\end{abstract}

\begin{tabular}{l} 
Experiencias en el sector de ocio y el principio de \\
inercia: Una analogía para pensar acerca de los \\
factores que influyen en la apropiación de espacios \\
públicos \\
Resumen: Resumen: En este artículo analizamos \\
la relación entre las fuerzas sociales y el uso de los \\
espacios públicos. La metodología se basó en la \\
participación, registro y descripción de las actividades \\
llevadas a cabo por UFPR PELC, entre 2008 y 2009 \\
en la región del distrito de Uberaba, en la ciudad de \\
Curitiba, Paraná. Para el análisis de los datos se \\
utilizó la analogía del principio del inercia en el plan \\
social y de las fuerzas principales mencionados: \\
las relaciones sociales, el liderazgo y la propiedad. \\
Se discute la necesidad de que estas fuerzas sean \\
mejoradas y ampliadas para que puedan contribuir a \\
la apropiación de espacios públicos para el deporte y \\
ocio de las ciudades. \\
Palabras clave: Centros de Ocio y Convivência. Políti- \\
cas Públicas. Valores Sociales. \\
\hline
\end{tabular}

\title{
REFERÊNCIAS
}

BAUMAN, Zygmunt; MAY, Tim. Aprendendo a pensar com a sociologia. Rio de Janeiro: Zahar, 2010.

BRASIL, 2007. Constituição da República Federativa do Brasil. Brasília: Supremo Tribunal Federal, 2003. cap. 2, art. 6. Disponível em: < http://www.stf.jus.br/portal/ constituicao/artigoBd.asp?item=136> . Acesso em: 17 fev. 2011.

Movimento, Porto Alegre, v. 17, n. 01, p. 117-136, janeiro/março de 2011. 
FRANÇA, R. Diálogos entre oferta e demanda: uma análise da relação entre o poder público e os grupos de ativismos sociais referentes aos parques da cidade de Curitiba. Dissertação (Mestrado) - Universidade Federal do Paraná, 2007.

FRANÇA, R.; RECHIA, Simone. O Estado do Paraná e seus espaços e equipamentos de esporte e lazer: apropriação, desapropriação ou reapropriação? In: CAVICHIOLLI, F. R.; MEZZADRI, F. M.; SOUZA, D. L. (Orgs.). Esporte e Lazer: Subsídios para o desenvolvimento e a gestão de políticas públicas. Jundiaí, SP: Fontoura, 2006. p. 61-74.

GASPAR, A. Física: série brasil. São Paulo: Ática, 2007.

JACOBS, Janes. Morte e vida das grandes cidades. São Paulo: Martins Fontes, 2000.

LEFEBVRE, Henri. O direito à cidade. São Paulo: Centauro, 2001.

LUCHIARI, M. T. D. P. A categoria espaço na teoria social. Temáticas, Campinas, v. 4, n. 7, p. 191-238, jan./jun. 1996.

MARCASSA, Luciana Pedrosa; MASCARENHAS, Fernando. Lazer. In: GONZÁLEZ, Fernando Jaime; FENSTERSEIFER, Paulo Evaldo (Orgs.). Dicionário Crítico de Educação Física. ljuí: Unijuí, 2005. v. 1. p. 255-259.

MARTELETO, Regina Maria. Análise das redes sociais: aplicação nos estudos de transferência da informação. Ciência da Informação, Brasília, v. 30, n. 1, p. 71-81, jan./abr. 2001.

PELLEGRIN, Ana de. Espaço de Lazer. In: GOMES, Christianne Luce (Org.). Dicionário Crítico do Lazer. Belo Horizonte: Autêntica, 2004. p.73-75.

RECHIA, Simone. Parques Públicos de Curitiba: A relação Cidade-Natureza nas experiências de Lazer. Tese (Doutorado) - Faculdade de Educação Física da Universidade Estadual de Campinas, 2003.

SANTOS, Milton. A natureza do espaço: técnicas e tempo, razão e emoção. 4. ed. São Paulo: Edusp, 2006.

SMOLKA, Ana Luiza Bustamante. O (im) próprio e o (im) pertinente na apropriação das práticas sociais. Caderno CEDES, Campinas, v.20, n. 50, p. 26- 40, abr. 2000.

Movimento, Porto Alegre, v. 17, n. 01, p. 117-136, janeiro/março de 2011. 
